\title{
Childhood Acute Monocytic Leukemia
}

National Cancer Institute

\section{Source}

National Cancer Institute. Childhood Acute Monocytic Leukemia. NCI Thesaurus. Code C9163.

An acute monocytic leukemia occurring in children. 